\title{
A percepção dos professores quanto à escola particular de educação infantil
}

\author{
Aictyr Lomonte da Silva' \\ Maria Eleusa Montenegro² \\ Ana Regina Melo Salviano ${ }^{3}$ \\ Celeida B. Garcia Cintra Pinto ${ }^{4}$ \\ Elenice Ribeiro dos Santos ${ }^{5}$ \\ Marianna Dantas Guimarães de Melo ${ }^{6}$
}

\section{Resumo}

Este artigo apresenta os resultados da pesquisa a respeito da percepção dos professores quanto às expectativas e às necessidades da Educação Infantil em escolas particulares do Distrito Federal. Foi utilizado o método qualitativo e, como instrumento, o questionário. Concluiu-se que os professores se encontravam preparados para a docência e satisfeitos com a profissão escolhida. A adaptação da criança à escola foi uma das dificuldades destacadas pelos professores, que acreditam que as relações interpessoais harmônicas entre professores, diretores, coordenadores, pais e alunos determinam a qualidade do trabalho pedagógico. Espera-se, com este trabalho, contribuir para que haja mais reflexão acerca do ensino na Educação Infantil.

Palavras-chave: Educação infantil. Prática pedagógica. Escola particular. Formação do professor.

1 Pedagoga pelo UniCEUB, professora de Educação Básica da Secretaria de Estado de Educação do Distrito Federal. aictyr@yahoo.com.br.

2 Pedagoga; orientadora educacional; administradora escolar; pós-doutora em Educação pela UnB; professora aposentada pela UFG; professora de Pedagogia do UniCEUB; líder do grupo de Pesquisa "Prática Pedagógica e Formação do Professor. memontenegro@ terra.com.br.

3 Pedagoga; orientadora educacional; administradora escolar; mestre em Educação pela FE/UnB (Currículo e Metodologia de Ensino); professora aposentada da SE-DF; professora do UniCEUB do curso de Pedagogia, das Licenciaturas e do Ciclo Básico.

4 Pedagoga; orientadora educacional; administradora escolar; psicopedagoga; mestre em educação pela UCB-DF; professora aposentada pela SEC-DF; professora de Pedagogia e Licenciaturas do UniCEUB. celeidacintra@uol.com.br.

5 Aluna do Ensino Médio no Centro Educacional GISNO e bolsista júnior do UniCEUB/ FAP/CNPq. elenicerdr@gmail.com.

6 Pedagoga pelo UniCEUB. mariannadgmelo@gmail.com. 


\section{Situando o assunto}

Este trabalho apresenta as necessidades e as expectativas dos professores de educação infantil da rede de ensino particular e a formação do professor que pretende atuar neste nível de ensino. Pretende também investigar, diante das mudanças governamentais realizadas nos últimos dez anos, se o profissional que atua na Educação Infantil se encontra preparado frente a esta realidade no Distrito Federal.

Compreende-se como Educação Infantil, aquela que atende pedagogicamente o período de vida escolar de crianças com idade entre 0 e 5 anos, isto com a implantação do Ensino Fundamental de nove anos. Este trabalho, no entanto, enfatiza a faixa etária compreendida entre 3 e 5 anos.

De acordo com a Lei de Diretrizes e Bases da Educação Nacional - LDB n ${ }^{\circ}$ 9.394/96, a instituição educacional que atende crianças de 0 a 3 anos é denominada creche, e a que atende crianças de 4 e 5 anos denomina-se infantil.

A Constituição Federal da República de 1988 (BRASIL, 1996) determinou, em seu art. 208, inciso IV, que a educação na faixa etária de 4 e 5 anos é dever do Estado e que essa responsabilidade caberia ao antigo Curso Normal (nível técnico), ou simplesmente, Magistério de segundo grau.

Com as alterações oriundas da LDB 9394/96, o Magistério, de nível técnico, foi suprimido, ficando determinado que todos os professores que atuassem na Educação Infantil deveriam ser graduados e que a conclusão desse processo seria por volta do ano 2010. De acordo com estas modificações, pretendeu-se prescrever, com esta Lei, a formação pedagógica mais qualificada e extensiva a esse nível de ensino, visto que é um período muito importante para o desenvolvimento e a aprendizagem e que, nessa fase, deverão ser desenvolvidas nas crianças todas as dimensões que as constituem, isto é, cognitiva, afetiva, social, motora e a psicológica.

Desse modo, o objetivo geral desse trabalho foi investigar, junto aos professores, as expectativas e as necessidades da Educação Infantil, verificando-se também a preparação desses profissionais para atuarem nesse nível de ensino. Assim, os objetivos específicos deste trabalho pretenderam: 
- Investigar, junto aos professores, as expectativas e as necessidades que emergem em relação à Educação Infantil.

- Investigar os procedimentos didático-metodológicos utilizados pelos professores e os resultados pedagógicos até então alcançados.

- Verificar a opinião dos professores quanto à preparação dos profissionais que atuam na Educação Infantil.

- Propor alternativas para aperfeiçoar o processo de formação do profissional da Educação Infantil, tendo em vista as expectativas da comunidade escolar do Distrito Federal.

\section{Procedimentos metodológicos}

Esta pesquisa foi realizada em seis escolas particulares que atuam na área de Educação Infantil e, para obtenção de resultados mais esclarecedores, posteriormente foram entregues questionários, para respostas pessoais, aos professores de escola pública.

A pesquisa desenvolveu-se em três etapas, assim organizadas: primeiramente foi analisada toda a legislação acerca da Educação Infantil nos últimos anos, de maneira que se estabelecessem parâmetros de comparação com a realidade educacional. Na segunda etapa, foi realizada investigação in loco junto às escolas particulares de Educação Infantil do Distrito Federal, por meio de questionários semiestruturados, como forma de verificar as expectativas e as necessidades de cada escola. Na última etapa discutiram-se os dados coletados, relacionando-os à legislação pertinente e à literatura atual acerca do assunto, chegando-se aos resultados do trabalho. A partir daí, propôs-se alternativas compatíveis com os anseios e os interesses emergentes na tentativa de, gradativamente, qualificar a Educação Infantil nas instituições, bem como na formação de profissionais para a área.

Para análise e discussão dos dados, utilizaram-se pressupostos das abordagens qualitativas e quantitativas, tendo sido adotados aqueles referentes à epistemologia qualitativa proposta por González Rey (2005, p. 5-8, grifos do autor), que a conceitua como sendo aquela que: 
Defende o caráter construtivo interpretativo do conhecimento, o que, de fato, implica compreender o conhecimento como produção e não como apropriação linear de uma realidade que nos apresenta.

Nesse sentido, realizou-se a coleta de dados e a busca, em material bibliográfico - livros e artigos -, da legislação que trata do assunto e de conhecimentos acerca das expectativas e das necessidades relacionadas à Educação Infantil com vistas a tecer e a criar construção teórica a respeito.

Os dados coletados foram organizados de maneira a proporcionar melhor apresentação/compreensão, visando à análise e à discussão do conteúdo. Para isso, foram definidas algumas categorias, quais sejam: a caracterização dos participantes da pesquisa; o trabalho pedagógico; as relações interpessoais; a formação para o trabalho e a realidade escolar.

O questionário, instrumento utilizado para a realização dessa coleta, foi elaborado com perguntas estruturadas e semiestruturadas, o que permitiu perceber a situação atual do grupo pesquisado.

Objetivou-se, na medida do possível, extrapolar a mera descrição do conteúdo do instrumento, buscando-se aprofundar a interpretação das respostas e, assim, construir o conhecimento.

Verificaram-se também referências importantes que caracterizassem os participantes, como idade, sexo, escolaridade e profissão que exercem.

\section{Análise e discussão dos dados: principais resultados}

\subsection{Caracterização dos participantes da pesquisa na escola particular}

Quanto à faixa etária das participantes da pesquisa, uma professora tinha menos de vinte anos de idade; quinze encontravam-se entre 20 e 30 anos de idade, portanto, faixa etária predominante; treze professoras estavam na faixa etária entre 31 e 40; oito estavam entre 41 e 50 anos de idade; uma entre 51 a 60 anos de idade e seis não responderam a pergunta. 
No que tange à formação acadêmica das docentes das escolas particulares, dez fizeram apenas o Magistério, dezessete concluíram a Graduação. Onze professoras fizeram Pós-graduação, e seis entrevistadas não responderam a esta pergunta.

Em relação ao tempo decorrido desde a conclusão do último curso realizado - técnico ou superior -, foram obtidos os seguintes dados: vinte e três participantes já estavam com até quatro anos de formadas na graduação; nove docentes tinham até nove anos desde a conclusão do último curso; três professoras tinham até quinze anos de formação; três entrevistadas tinham mais de vinte anos; duas professoras estavam cursando a graduação e apenas quatro docentes não responderam.

Quanto ao tempo de experiência das participantes na Educação Infantil, verificou-se que dezenove docentes tinham até três anos na regência desta modalidade de ensino; onze professoras já tinham entre quatro e seis anos de experiência atuando na Educação Infantil; oito docentes estavam, no mínimo, há sete anos e no máximo há dez anos nesta experiência; e seis professoras tinham mais de dezesseis anos de prática.

\subsection{0 trabalho pedagógico}

Em relação ao trabalho pedagógico desenvolvido, foram observados os projetos aplicados na Educação Infantil, e quinze professoras relataram desenvolver projetos em sua rotina da sala de aula, contudo, as demais regentes não responderam a esta pergunta. As professoras que trabalhavam com projetos destacaram: Projeto Criança - CNPq; Roda de Leitura; Projeto da Saúde; Projeto de Horta; Projeto de Meio Ambiente; Projeto Folclore; Projeto Autoestima; Projeto Semana da Alimentação e de Incentivo à Leitura.

Na opinião das participantes, dentre os atributos que um professor de Educação Infantil deve ter, ficou evidenciado que amor, carinho e paciência estão em primeiro lugar e, em segundo, a formação adequada para a atuação nessa modalidade de ensino e o conhecimento da faixa etária das crianças. Outros atributos ci- 
tados foram: compromisso, determinação, flexibilidade, dinamismo, mediação de conhecimentos, respeito às diferenças, gosto pela profissão e por crianças. Dentre as participantes, dez não responderam a pergunta. Segundo Libâneo (1994, p. 28), “[...] é verdade que muitos professores manifestam especial tendência e gosto pela profissão, assim como se sabe que mais tempo de experiência ajuda no desempenho profissional". Entretanto, conforme escreve o autor:

[...] domínio das bases teórico-científicas e técnicas, e sua articulação com as exigências concretas do ensino, permitem maior segurança profissional, de modo que o docente ganhe base para pensar sua prática e aprimore sempre mais a qualidade do seu trabalho.

Perguntadas se existem algumas dificuldades ao assumir uma nova turma de Educação Infantil, a maioria das professoras concordou que a adaptação das crianças ao novo ambiente e à nova professora, no início do ano, é o momento mais difícil. Em seguida, vem a insegurança e a falta de confiança das famílias em relação ao trabalho do professor, o que dificulta a realização do trabalho pedagógico. Conhecer e perceber as particularidades de cada criança aparece como a terceira dificuldade. Somente uma participante afirmou não ter nenhuma dificuldade ao receber uma nova turma.

Quanto à avaliação que fariam a respeito da qualidade do trabalho das demais professoras, as respostas foram variadas: uma participante respondeu que o trabalho pedagógico era péssimo, mas todas as demais responderam que o trabalho pedagógico desenvolvido pelas professoras da escola em que atuam era ótimo ou excelente; uma professora informou que a cada dia aprende com os colegas atividades diferenciadas, tais como, música ou uma história, considerando que existe uma troca muito gratificante; outra participante afirmou não ter conhecimento suficiente para avaliar o trabalho das demais professoras.

Para o tópico acerca do planejamento pedagógico, grande parte das professoras descreveu que nas escolas onde trabalha, ele existe e que elas participam de sua elaboração e de sua execução. Todavia, é relevante salientar que seis docentes responderam que não participaram da elaboração desse documento. Segundo Libâneo (1994, p. 230), o plano da escola é: 
[...] o plano pedagógico e administrativo da unidade escolar, onde se explicita a concepção pedagógica do corpo docente, as bases teórico-metodológicas da organização didática, a contextualização social, econômica, política e cultural da escola, a caracterização da clientela escolar, os objetivos educacionais gerais, a estrutura curricular, diretrizes metodológicas gerais, o sistema de avaliação do plano, a estrutura organizacional e administrativa.

Outro aspecto analisado foi em relação à execução das atividades relacionadas às datas comemorativas. Nesse ponto, o grupo ficou dividido. Onze professoras responderam que todas as atividades relacionadas às comemorações que envolvam decoração das instalações da escola devem ser realizadas pelas crianças, sob a supervisão dos professores; mas dezenove responderam que é de responsabilidade apenas do professor. Nesse sentido, uma docente afirmou ser uma "perda de tempo e exploração", dos professores terem de decorar a sala de aula e a escola, para as festividades, enquanto as demais são a favor da participação dos professores na ornamentação das salas e da escola em datas festivas.

Segundo os dados coletados, as escolas em que as docentes atuam não adotam pedagogia tradicional, proporcionando, assim, mais liberdade à criatividade.

\subsection{Realidade escolar}

Para caracterizar a realidade escolar vivenciada, as participantes responderam a questionamentos referentes à estrutura física da escola, à participação da família e à interação entre professores/pais/escola.

$\mathrm{Na}$ avaliação docente com relação à infraestrutura e aos recursos didáticos necessários à aprendizagem dos alunos, as participantes afirmaram que na escola existe esta estrutura: salas de leitura, bibliotecas, sala de artes, computadores, sala de vídeo, cozinha, auditório, parque e jogos pedagógicos, tudo compondo a realidade da maior parte das entrevistadas. Apenas uma docente enfatizou não existir tal estrutura em sua escola. Portanto, a maioria das participantes concordou que a escola em que atua oferece condições necessárias para o desenvolvimento do trabalho pedagógico e apenas três professoras discordaram da questão. 
A estruturação do espaço, a forma como os materiais estão organizados, a qualidade e adequação dos mesmos são elementos essenciais de um projeto educativo. Espaço físico, materiais, brinquedos, instrumentos sonoros e mobiliários não devem ser vistos como elementos passivos, mas como componentes ativos do processo educacional que refletem a concepção de educação assumida pela instituição. Constituem-se em poderosos auxiliares da aprendizagem (BRASIL, 1998, p. 68).

Quanto aos recursos didáticos disponíveis, doze participantes relataram que não são suficientes para desenvolver as competências e habilidades previstas no planejamento e as demais entrevistadas concordaram que os recursos oferecidos estavam de acordo com as necessidades. Segundo o Referencial Curricular Nacional para a Educação Infantil (BRASIL, 1998, p. 47-48):

A definição de objetivos em termos de capacidades - e não de comportamentos - visa ampliar a possibilidade de concretização das intenções educativas, uma vez as capacidades se expressam por meio de diversos comportamentos e as aprendizagens que convergem para ela podem ser de naturezas diversas. Ao estabelecer objetivos nesses termos, o professor amplia suas possibilidades de atendimento à diversidade apresentada pelas crianças, podendo considerar diferentes habilidades, interesses e maneiras de aprender no desenvolvimento de cada capacidade. Elas podem ser de ordem física, cognitiva, afetiva, ética, relação interpessoal e de inserção social.

No tocante à autonomia das professoras para desenvolverem projetos pedagógicos, dezoito participantes mencionaram que, na escola onde atuam, foram estimuladas a elaborar projetos de acordo com a necessidade de cada turma. As demais participantes não responderam a essa pergunta.

Elaborar e implantar um projeto educativo requer das equipes de profissionais das instituições um grande esforço conjunto. A direção da instituição tem um papel chave neste processo quando auxilia a criação de um clima democrático e pluralista (BRASIL, 1998, p. 67).

No que se refere à interação escola e órgãos ligados aos direitos da criança, notou-se que nove entrevistadas afirmaram existir esta relação. 
Em relação à participação dos pais no sucesso do processo ensino-aprendizagem das crianças, a maioria das participantes concordou ser uma parceria benéfica para o desenvolvimento dos alunos, enquanto três docentes não concordaram com esta situação. Nesse ponto, cinco docentes afirmaram que os pais não têm formação adequada para interferir no trabalho da escola, e as demais salientaram que os pais têm sim formação adequada para opinar no trabalho escolar. Ressalte-se que, todas as docentes afirmaram que os pais devem acompanhar diariamente as tarefas escolares de seus filhos e quase todas opinaram sentirem-se preparadas para receber sugestões dos pais em relação à prática pedagógica desenvolvida em sala de aula.

Os professores parecem se esquecer da importância dos pais no desenvolvimento e na aprendizagem dos alunos. Nesse aspecto, Souza (2006, p. 104) tem uma contribuição importante:

De fato, nós, pais e professores, somos para os nossos filhos como verdadeiros espelhos, onde se refletem a vida, o mundo, as formas das relações pessoais e sociais. Em geral, seus olhos nos veem como heróis, ídolos ou sábios e como detentores de todo conhecimento do mundo. Ademais, tendemos a ser, para eles a referência maior, da moral, da ética, dos valores, do poder e da verdade. A forma como nós, pais e mestres, vemos o outro e o mundo e nos comportamos diante deles, acaba por influenciar as aprendizagens e as posturas assumidas por nossos filhos ou alunos diante disso.

Quanto à assiduidade da família às reuniões escolares, dezenove participantes afirmaram que nem sempre é possível contar com a presença dela, acreditando ser fundamental a participação da família na elaboração e na intervenção do projeto político pedagógico da escola.

Todos os participantes disseram que a família deve colaborar na parte de eventos e na conservação da parte física da escola, demonstrando a importância da sua participação na escola, valorizando, portanto, sua presença. Nesse sentido, pode-se confirmar que: 


\begin{abstract}
conseguirem fazer isto, estarão contribuindo nas interações positivas entre a família e a escola e possibilitando o próprio desenvolvimento da autonomia e da própria cidadania das crianças (GOMES, 2002, p. 9).
\end{abstract}

Quanto à educação integral, duas docentes responderam que professores que trabalham o dia todo são menos produtivos que os demais, devido ao desgaste físico e mental. Para dar suporte e apoio ao trabalho com a Educação Infantil, três participantes afirmaram que a escola conta com a colaboração de outros profissionais como nutricionista e psicólogo, entre outros.

\title{
3.4 Relações interpessoais
}

No ambiente escolar, as relações interpessoais acontecem em várias situações. Tem-se a relação professor-aluno; aluno-aluno; professores-responsáveis e professor-coordenação da escola. Dependendo da postura na forma de trabalho da instituição escolar, os conflitos decorrentes destas relações podem ser modificados positivamente, havendo crescimento de todos os envolvidos. Caso contrário, esses conflitos geram desconforto e insegurança para as famílias e profissionais da escola.

O ambiente de cooperação e respeito entre os profissionais e entre esses e as famílias favorece a busca de uma linha coerente de ação. Respeito às diferenças, explicitação de conflitos, cooperação, complementação, negociação e procura de soluções e acordos devem ser a base das relações entre adultos (BRASIL, 1998, p. 6).

As professoras apontaram as principais dificuldades de relacionamento na relação professor-aluno e, nesse aspecto, a adaptação da criança à classe de Educação Infantil foi o ponto mais citado, sendo esta a maior dificuldade da relação. Cinco participantes afirmaram que a maior dificuldade encontrada está relacionada à falta de limites e uma professora salientou que a falta de limites em casa dificulta a construção do estudante em sala de aula. Duas profissionais afirmaram que a falta de respeito é a maior dificuldade. Duas docentes disseram não existir dificuldades na relação professor-aluno e uma professora descreveu que as crianças são muito carinhosas e atenciosas, não existindo, por isso, dificuldades de relacionamento. 
Uma professora relatou que tem um aluno com dificuldade na fala e que, em alguns momentos, ela não consegue compreender o que a criança diz, dificultando, assim, seu relacionamento com essa criança. Quanto a esse aspecto, Libâneo (1994, p. 250) afirma que “[...] o trabalho docente se caracteriza por um constante vaivém entre as tarefas cognoscitivas colocadas pelo professor e o nível de preparo para resolverem as tarefas". E afirma ainda que:

Na sala de aula o professor exerce uma autoridade, fruto de qualidades intelectuais, morais e técnicas. Ela é um atributo da condição profissional do professor e é exercida como estímulo e ajuda para o desenvolvimento independente dos alunos. O professor estabelece objetivos sociais e pedagógicos, seleciona e organiza os conteúdos, escolhe métodos, organiza a classe. Entretanto, essas ações docentes devem orientar os alunos para que respondam a elas como sujeitos ativos e independentes. A autoridade deve fecundar a relação educativa e não cercá-la (LIBÂNEO, 1994, p. 251).

Quanto à relação aluno-aluno, quatorze participantes relataram que o "egocentrismo" é a maior dificuldade de relacionamento entre as criança, gerando vários conflitos em sala de aula, como, por exemplo, brigas na disputa por brinquedos, espaço e objetos. "O espaço na instituição de educação infantil deve propiciar condições para que as crianças possam usufruí-lo em benefício do seu desenvolvimento e aprendizagem" (BRASIL, 1998, p. 69).

Com respeito à relação professores-responsáveis, sete participantes apresentaram como maior dificuldade a falta de cooperação da família com a escola. $\mathrm{Na}$ maioria das vezes, segundo as participantes, os pais tentam descumprir as regras da escola, são ausentes nas reuniões escolares ou não conferem diariamente a agenda escolar do filho. A falta de tempo da família para acompanhar a vida escolar do filho dificulta a relação família-escola. Outro aspecto relevante levantado pelas docentes é o equívoco que algumas famílias cometem tratando a professora como "babá". Uma docente relatou que, em alguns momentos, os pais querem ensinar a professora o que deve ser trabalhado em sala de aula. Duas regentes declararam que, quando há diálogo entre a família e a escola, a confiança se fortalece, fazendo com que o trabalho em sala de aula seja prazeroso tanto para o professor quanto para o aluno. 
Com referência à relação entre professor e coordenação, sete professoras apontaram que a maior dificuldade está na falta de comunicação clara e objetiva com coordenadores e a falta de diálogo aparece como o ponto mais citado neste tópico. Em segundo lugar, as participantes mencionaram o despreparo do coordenador para lidar com situações cotidianas da Educação Infantil. A falta de liberdade e a dificuldade de expor novas ideias também foram apontadas como dificuldades nessa relação. Uma docente relatou que a “[...] coordenação e o professor devem trabalhar juntos para um bom desenvolvimento e aprendizagem do aluno”. De acordo com os dados coletados, percebe-se que há necessidade de os professores estarem articulados com os coordenadores e abrirem um espaço para que ambos se posicionem nos aspectos profissionais, e possam, assim, permitir que aflorem as questões vividas. Portanto, esta intenção fica clara, na voz de Almeida (2000, p. 85), quando afirma que:

[...] o dar ao outro a possibilidade de posicionar-se como pessoa - significa aceitar que seu desempenho não depende tanto do que sabe, ou não sabe, mas do que é, de sua relação com o saber, com o aluno, com o colega, com a escola, com a profissão. É preciso que haja espaço para ser ouvido, para falar $[\ldots]$.

Outro ponto essencial foi analisado nessa categoria: as participantes deveriam assinalar se a escola em que atuam promove o relacionamento harmonioso entre os profissionais, melhorando o processo ensino-aprendizagem. Deve-se enfatizar que trinta e três docentes assinalaram que a escola promove o relacionamento harmonioso, enquanto onze professoras afirmaram que não.

A maioria das participantes disse acreditar que as relações interpessoais na escola determinam a qualidade do trabalho pedagógico e, por isso, professores, diretores e coordenadores devem primar pelo convívio harmônico, minimizando a competição. Contudo, quatro regentes não concordaram que essas relações seriam responsáveis pela qualidade do trabalho pedagógico.

Percebeu-se que quatro professoras salientaram que não existe troca de experiências na escola onde trabalham, mas, as demais participantes afirmaram haver, na instituição onde atuam, troca de ideias e de experiências para enriquecer 
o trabalho pedagógico da escola. Dezoito docentes afirmaram que são incentivadas a buscar informações e atuar por si próprias. Quando questionadas acerca do posicionamento que a escola deve ter quanto ao relacionamento harmonioso entre profissionais, família e alunos, somente uma participante revelou que tal posicionamento não existe na escola em que trabalha.

\subsection{Formação para o trabalho}

Em relação aos cursos realizados na área de Educação Infantil, quatro professoras não responderam a essa pergunta, uma docente afirmou não ter feito curso na área, e as demais participantes declararam que fizeram, pelo menos, um curso em Educação Infantil.

Outro fator fundamental para a pesquisa foi saber a opinião das participantes quanto aos conteúdos ministrados no curso de Pedagogia e a realidade encontrada nas escolas. Em se tratando desse aspecto, vale ressaltar que as professoras foram unânimes em afirmar que existe uma longa distância entre a teoria ensinada na graduação e a prática vivenciada em sala de aula. As participantes afirmaram acreditar que a teoria complementa a prática, mas que falta a contextualização com as condições reais de ensino e aprendizagem nas escolas. Não obstante, uma participante afirmou que o período de estágio foi importante para mostrar aos discentes que tipo de realidade encontrariam, direcionando-os, assim, à prática.

Em relação à necessidade que as professoras sentem de mais formação para desenvolverem um bom trabalho pedagógico na escola em que atuam, nove profissionais afirmaram encontrarem-se nessa situação. A mesma quantidade de docentes (nove) assegurou estar satisfeita com sua preparação para atuar na Educação Infantil e dez participantes revelaram que sempre realizam cursos voltados para a Educação Infantil. Dentre estas, quatro docentes concordaram que as teorias ou tendências pedagógicas estudadas durante a graduação nada têm a ver com a realidade escolar em que atuam. É importante lembrar que: 
Pensar a prática não é somente pensar a ação pedagógica na sala de aula, nem mesmo a colaboração didática com os colegas. É pensar a profissão, a carreira, as relações de trabalho e de poder nas organizações escolares, a parte de autonomia e de responsabilidade conferidas aos professores, individual ou coletivamente (PERRENOUD, 1993, p. 1995).

Quanto ao curso de Pedagogia como formador do educador, onze professoras disseram acreditar ser o percurso mais indicado para os profissionais que pretendem atuar na Educação Infantil.

A formação continuada enfatizada pelas professoras significa que “[...] estar em formação implica investimento pessoal, um trabalho livre e criativo sobre os percursos e sobre os projetos próprios com vista à construção de uma identidade, que é também uma identidade profissional" (NÓVOA, 1992, p. 25).

Quando foi discutida a valorização do trabalho realizado na Educação Infantil, apenas três professoras afirmaram que isso ocorre; três concordaram que é uma função muito estressante e quatorze afirmaram que o trabalho pedagógico na Educação Infantil é excessivamente mais exigente que nas demais modalidades de ensino, portanto, deveria ser mais bem remunerado.

Mesmo conhecendo todas as dificuldades inerentes ao magistério, a maioria das participantes está satisfeita com a profissão que escolheu e apenas duas regentes afirmaram que deixarão a Educação Infantil quando conseguirem outro emprego.

\section{Reflexões finais}

Pode-se perceber por este trabalho que, no que tange à formação acadêmica das docentes das escolas particulares, dez fizeram apenas o magistério e, dezessete concluíram a graduação. Outras onze professoras fizeram pós-graduação e seis entrevistadas não responderam a esta pergunta, o que possibilita a conclusão de que os professores desse nível de ensino estão preparados para a docência no tocante à formação profissional. 
Em relação ao tempo de experiência das participantes na Educação Infantil, verificou-se que a maioria encontrava-se com mais de quatro anos na regência nesta modalidade de ensino, apesar de que, se verificada a faixa etária, percebeu-se que a predominância estava com professores de até três anos de experiência.

Foi importante perceber que, apesar de todas as dificuldades inerentes ao magistério, e as professoras vivenciam isto, a maioria das participantes está satisfeita com a profissão que escolheu e apenas duas regentes afirmaram que deixarão a Educação Infantil quando conseguirem outro emprego.

As principais características e atributos de um professor de Educação Infantil destacados pelas participantes devem ser: amor, carinho e paciência - em primeiro lugar - e, em segundo, a formação adequada para a atuação nessa modalidade de ensino e o conhecimento da faixa etária das crianças.

A formação continuada é promovida nas instituições onde trabalham vinte e oito docentes, enquanto para dezesseis participantes não há a promoção dessa formação. Sete docentes afirmaram que as teorias ou tendências pedagógicas estudadas durante a graduação nada têm a ver com a realidade escolar em que atuam. As participantes consideram ser fundamental a participação da família na elaboração e na intervenção do projeto político pedagógico da escola, apesar de não se contar sistematicamente com a presença da família nas reuniões escolares.

A adaptação da criança ao ambiente de sala de aula de Educação Infantil é uma das principais dificuldades destacadas pelos professores, sendo apresentadas, ainda, as faltas de limites e de respeito como maiores dificuldades.

Pelos dados apresentados, percebeu-se que a maior dificuldade que as professores sentem em relação aos coordenadores está na falta de comunicação clara e objetiva, bem como a falta de diálogo e o despreparo do gestor para lidar com situações cotidianas da Educação Infantil. A falta de liberdade e a dificuldade de expor novas ideias também foram apontadas como empecilhos nessa relação. A maioria das participantes afirmou acreditar que as relações interpessoais na escola determinam a qualidade do trabalho pedagógico e, por isso, professores, 
diretores e coordenadores devem primar pelo convívio harmônico, minimizando a competição.

Considerou-se que, pelo número de professoras que participaram da pesquisa, pode-se estabelecer uma percepção indicativa da situação da Educação Infantil no Distrito Federal.

Esta pesquisa faz parte de uma pesquisa maior que abrangerá também a participação de professores de escolas públicas. Vale ressaltar que já foram realizadas pesquisas com gestores e pais das escolas públicas e particulares. Todos esses dados reunidos aprofundarão os resultados da pesquisa, uma vez que se pretende, ao final, obter resultados contributivos para melhoria do processo de formação do educador no Distrito Federal e a divulgação dos resultados em eventos e em periódicos científicos, em nível regional, nacional e internacional.

Esses resultados poderão servir de base para reflexões entre profissionais desse nível de ensino e fornecer elementos que contribuam com as instituições de Educação Infantil, abrindo oportunidades para a continuação dos estudos, levando a novos projetos, seminários, fóruns e debates.

\section{School teachers and their perceptions regarding private Early Childhood Education schools}
Abstract
This paper presents the results of a survey regarding the perceptions of scho- ol teachers about expectations and needs for Early Childhood Education in Distri- to Federal private schools. The qualitative method was used and a questionary was the instrument. Conclusion was that teachers were duly prepared for teaching and pleased with their chosen profession. Adaptation of the child to school was one of the difficulties pointed out by teachers, who believe harmonious interpersonal relations among teachers, principals, coordinators, parents and students are decisi- ve for quality in the pedagogical work. It is expected that this study will contribute towards a deeper reflection about teaching in Early Childhood Education. 
Keywords: Early childhood education. Pedagogical practice. Private school. Teacher training.

\section{Referências}

ALMEIDA, Laurinda Ramalho. A dimensão relacional no processo de formação docente: uma abordagem possível. In: BRUNO, Eliane Bambini Gorgueira (Org.). O coordenador pedagógico e a formação docente. 2. ed. São Paulo: Loyola, 2000. p. 86.

BRASIL. Constituição (1988). Constituição da República Federativa do Brasil de 1988. Disponível em: <http://www.presidencia.gov.br>. Acesso em: 15 mar. 2006.

BRASIL. Ministério da Educação. Lei no. 9394, de 20 de dezembro de 1996. Estabelece as diretrizes e bases da educação nacional. Disponível em: <http://www.planalto. gov.br/ccivil_03/Leis/L9394.htm>. Acesso em: 15 mar. 2006.

BRASIL. Referencial curricular nacional para a educação infantil: introdução. Brasília: MEC/SEF, 1998.

GOMES, Gizelha Maria Pereira. A família e o processo de ensino e de aprendizagem. Revista do Curso de Pedagogia, Brasília, v. 1, n. 1, p. 7-10, jul./dez. 2002.

GONZÁLEZ REY, Fernando. Pesquisa qualitativa e subjetividade: os processos de construção da informação. São Paulo: Thomson, 2005.

LIBÂNEO, José Carlos. Didática. São Paulo: Cortez, 1994.

NÓVOA, A. (Coord.). Os professores e sua formação. Lisboa: Dom Quixote/IIE, 1992.

PERRENOUD, P. Práticas pedagógicas, profissão docente e formação. Lisboa: Dom Quixote, 1993.

SOUZA, Maria de Fátima G. de. A aprendizagem, desenvolvimento e trabalho pedagógico na educação infantil: significados e qualidades. In:

TACCA, Maria Carmen V. R. (Org.). A aprendizagem e o trabalho pedagógico. Campinas: Alínea, 2006. 


\section{Para publicar na revista Universitas Humanas, acesse 0 endereço eletrônico www.publicacoesacademicas.uniceub.br. Observe as normas de publicação, para facilitar e agilizar o trabalho de edição.}

